\title{
Influence of self-perceived oral health and socioeconomic predictors on the utilization of dental care services by schoolchildren
}

\section{Chaiana Piovesan ${ }^{(a)}$ \\ José Leopoldo Ferreira Antunes ${ }^{(b)}$ \\ Renata Saraiva Guedes ${ }^{(c)}$ \\ Thiago Machado Ardenghi(c)}

(a) Department of Orthodontics and Pediatric Dentistry, School of Dentistry, University of São Paulo, São Paulo, SP, Brazil.

(b) Department of Epidemiology, School of Public Health, University of São Paulo, São Paulo, SP, Brazil.

(c)Department of Stomatology, Federal University of Santa Maria, Santa Maria, RS, Brazil.
Corresponding author:

Chaiana Piovesan

Rua José Alves Cunha Lima, 159, apto.

7034, Butantã

São Paulo - SP - Brazil

CEP - 05360-050

Email: chaiana@usp.br

Received for publication on Sep 13, 2010 Accepted for publication on Dec 10, 2010
Abstract: The influence of socioeconomic factors and self-rated oral health on children's dental health assistance was assessed. This study followed a cross-sectional design, with a multistage random sample of 792 12-year-old schoolchildren from Santa Maria, a city in southern Brazil. A dental examination provided information on the prevalence of dental caries (DMFT index). Data about the use of dental service, socioeconomic status, and self-perceived oral health were collected by means of structured interviews. These associations were assessed using Poisson regression models (prevalence ratio; $95 \%$ confidence interval). The prevalence of regular use of dental service was $47.8 \%$. Children from low socioeconomic backgrounds and those who rated their oral health as "poor" used the service less frequently. The distribution of the kind of oral healthcare assistance used (public/private) varied across socioeconomic groups. The better-off children were less likely to have used the public service. Clinical, socioeconomic, and psychosocial factors were strong predictors for the utilization of dental care services by schoolchildren.

Descriptors: Dental Health Service; Socioeconomic Factors; Dental Caries.

\section{Introduction}

Disparities have been noted in the use of oral healthcare assistance in several countries, mainly among disadvantaged groups. ${ }^{1-4}$ However, in most developing countries, data about utilization of dental care services by schoolchildren are scarce. ${ }^{1,2,5-7}$

In the Brazilian context, data from official publications demonstrated that $18.4 \%$ of the population aged between 10 and 14 years had never visited the dentist. ${ }^{8}$ There is regional inequality in the use of healthcare service because of socioeconomic development; only a low percentage of the population had never visited the dentist in the most developed Brazilian regions. ${ }^{8}$

The use of dental care service may be influenced by socioeconomic and psychosocial factors. ${ }^{1,9-11}$ However, data about the interaction among the different predictors of dental care service utilization in representative samples have been rarely assessed for Brazilian schoolchildren. The most important determinants of dental service utilization noted in Bra- 
zilian adolescents are a high socioeconomic status and schooling. ${ }^{12}$ Nevertheless, higher prevalence of dental care system utilization was observed in individuals who rated their oral health as "good" than in those who rated theirs as "poor." 12

The perception of oral health may influence oral health decisions and healthcare utilization patterns and may be associated with clinical and socioeconomic conditions. ${ }^{13,14}$ However, the relation between dental care service utilization and the perception of oral health in schoolchildren is inconclusive. ${ }^{13,15}$

Understanding the impact of socioeconomic and psychosocial predictors of oral healthcare utilization could be useful for planning public health policies, and could thus lead to a better allocation of resources. ${ }^{2}$ In this cross-sectional study on a representative sample of 12-year-old Brazilian children, we assessed the influence of socioeconomic factors and self-rated oral health on the utilization of dental health services by schoolchildren.

\section{Methods \\ Sample}

A survey was conducted to assess the oral health status of a representative sample of 12-year-old schoolchildren (351 boys and 441 girls) living in Santa Maria, RS, a city in southern Brazil. The city has 263,403 inhabitants, ${ }^{8}$ with nearly $85 \%$ of the 12 -year-old children enrolled in public schools and residing in the city. A multistage sampling considered all public schools as the primary survey units; therefore, 20 out of 39 schools were randomly selected. A random sample of children was selected from a list encompassing all students enrolled in these 20 selected schools. Only those subjects who were intellectually and physically capable of responding to the questionnaire were included in the study.

For the sample calculation to assess the prevalence of regular use of dental service, the following parameters were adopted: 5\% standard error, 95\% confidence interval level, and expected prevalence of $47 \% .{ }^{6}$ In addition, we applied a design effect of 1.4 and $10 \%$ addition to non-response. A minimum sample size of 590 children was estimated to satisfy these requirements. To explore the association between regular use of service and independent vari- ables, the following parameters were adopted: 5\% standard error, $80 \%$ power, $95 \%$ confidence interval, 1.4 design effect, $10 \%$ to non-response, ratio of unexposed to exposed of $2: 1$, and a prevalence ratio of at least $1.7 .^{1}$

The actual number of participants (792) was larger than the minimum (770) number required by these parameters.

\section{Data collection}

For data collection, dental examinations and structured interviews were conducted by 6 examiners and 6 interviewers, respectively. These 12 participants were trained and calibrated for 36 hours for data collection.

Dental examination was conducted as per the international criteria standardized for oral health survey by the World Health Organization (WHO). ${ }^{16}$ The children were examined in a room with natural light, using community periodontal index (CPI) probes (WHO probe; Golgran, Brazil) and plane dental mirrors (dental plane mirror no. 5; Golgran, Brazil). The occurrence of untreated caries was noted in the clinical examination (corresponding to a non-zero D component in the DMFT indices).

Data on the socioeconomic characteristics and use of dental service were collected from parents. The questionnaire provided information on age, gender, skin color, parents' educational level, and household income. For educational level, we compared the education of those parents who had completed 8 years of formal schooling, which in Brazil corresponds to primary school, with those who had not. Household income was measured in terms of the Brazilian minimum wage, a standard used for this type of assessment, which nearly corresponded to 280 US dollars during the data-gathering period. Occupational status discriminated between employed and unemployed parents. The questionnaire was also used to collect our dependent variables: whether the child had visited any dental care service in the previous 6 months and the type of healthcare service used (private or public). The feasibility of the socioeconomic questionnaire had been previously assessed in a sample of 20 parents during the calibration process. These parents were not included in 
the final sample.

Data about the self-perception of oral health were measured by the following question: "Would you say that your oral health is (1) excellent, (2) good, (3) fair, or (4) poor?" The response to this question was dichotomized into good (codes 1 and 2 ) and poor (codes 3 and 4) oral health. The feasibility of this questionnaire had been previously assessed in a sample of 20 children during the calibration process.

\section{Data analysis}

The data were analyzed through the STATA 9.0 software (Stata Corporation, College Station, TX, USA). Unadjusted analyses were accomplished to provide a summary of statistics and a preliminary assessment of the association between the predictor variables and outcomes. Two outcomes were considered in the analyses: the prevalence of children who had sought dental care service in the previous 6 months and the type of healthcare used (public/ private).

A Poisson regression model was used to assess the association between the predictor variables and outcomes. A backward stepwise procedure was used to include or exclude explanatory variables in the adjustments for the models. Explanatory variables presenting a $p$ value $\leq 0.20$ in the assessment of correlation to each outcome (bivariate analyses) were included in the adjustments for the model. Explanatory variables were selected for the final models only if these variables had a $p$ value of $\leq 0.05$ after adjustment.

\section{Ethics}

The study protocol was approved by the Human Research Ethics Committee from the Federal University of Santa Maria.

\section{Results}

This study included 792 children in total $(44.3 \%$ boys and $55.7 \%$ girls). The response rate was $90 \%$. Non-participation was mainly due to the children remaining absent on the day scheduled for the examination or forgetting to bring the consent form signed by their parents. Inter- and intra-examiner agreement (Kappa statistics) for dental caries ranged from 0.77 to 0.95 and from 0.80 to 0.94 , respectively.

Table 1 summarizes sample distribution based on demographic characteristics and socioeconomic and clinical status of the subjects. The children were predominantly white, and their parents mostly had a low educational level. More than half of the families earned less than twice the Brazilian minimum wage. The prevalence of untreated caries was $39.3 \%$.

Of all the children included in the study, only 47.8\% (95\% confidence interval: 44.3\%-51.4\%) had visited the dentist (Table 2). Children who rated their oral health as "fair/poor," whose mothers did not complete primary education, and who were without caries were less likely to have used dental service in the previous 6 months.

There is an association between the type of ser-

Table 1 - Clinical and demographic characteristics of the sample.

\begin{tabular}{|c|c|c|}
\hline Variable & $\mathrm{n}$ & $(\%)$ \\
\hline \multicolumn{3}{|l|}{ Sex } \\
\hline Boys & 351 & 44.3 \\
\hline Girls & 441 & 55.7 \\
\hline \multicolumn{3}{|l|}{ Skin colour* } \\
\hline White & 609 & 77.8 \\
\hline Non-white & 174 & 22.2 \\
\hline \multicolumn{3}{|l|}{ Household Income* } \\
\hline$\geq 2$ Brazilian minimum wages & 341 & 51.1 \\
\hline$<2$ Brazilian minimum wages & 326 & 48.9 \\
\hline \multicolumn{3}{|l|}{ Mother's education* } \\
\hline$\geq 8$ years & 330 & 43.1 \\
\hline$<8$ years & 434 & 56.8 \\
\hline \multicolumn{3}{|l|}{ Father's education* } \\
\hline$\geq 8$ years & 273 & 40.0 \\
\hline$<8$ years & 465 & 63.0 \\
\hline \multicolumn{3}{|l|}{ Dental caries } \\
\hline $\mathrm{DMF}=0$ & 481 & 60.7 \\
\hline $\mathrm{DMF}>0$ & 311 & 39.3 \\
\hline \multicolumn{3}{|l|}{ Self-rated oral health* } \\
\hline Good-excellent & 389 & 49.1 \\
\hline Fair-poor & 403 & 50.9 \\
\hline
\end{tabular}


Table 2 - Predictors of dental care system use within previous 6 months (Prevalence ratio: $\mathrm{Cl}$ 95\%).

\begin{tabular}{|c|c|c|c|c|}
\hline \multirow{2}{*}{ Variables } & \multirow{2}{*}{$\mathrm{n}$} & \multicolumn{3}{|c|}{ Visited the service } \\
\hline & & n (\%) & PR (Cl 95\%) & $\mathrm{PR}_{\text {adj }}(\mathrm{Cl} 95 \%)$ \\
\hline Sex & 751 & 359 (47.8) & $p=0.64$ & \\
\hline Boys & 333 & $156(43.4)$ & 1 & \\
\hline Girls & 418 & $203(56.5)$ & $1.03(0.89-1.20)$ & \\
\hline Skin colour & 743 & $352(47.4)$ & $p=0.06$ & $* *$ \\
\hline White & 581 & $286(49.3)$ & 1 & \\
\hline Non-white & 162 & $66(40.7)$ & $0.82(0.67-1.01)$ & \\
\hline Household income & 639 & $297(46.5)$ & $p=0.07$ & $* *$ \\
\hline$\geq 2$ Brazilian minimum wages & 331 & $165(49.8)$ & 1 & \\
\hline$<2$ Brazilian minimum wages & 308 & $132(42.8)$ & $0.85(0.72-1.01)$ & \\
\hline Mother's education & 727 & $346(47.6)$ & $p=0.02$ & $p=0.02$ \\
\hline$\geq 8$ years & 319 & $167(52.3)$ & 1 & 1 \\
\hline$<8$ years & 408 & 179 (43.9) & $0.83(0.72-0.97)$ & $0.83(0.71-0.96)$ \\
\hline Father's education & 703 & $336(47.8)$ & $p=0.01$ & $* *$ \\
\hline$\geq 8$ years & 266 & $142(53.4)$ & 1 & \\
\hline$<8$ years & 437 & $194(44.4)$ & $0.83(0.71-0.96)$ & \\
\hline Dental caries & 751 & 359 (47.8) & $p=0.03$ & $p=0.02$ \\
\hline $\mathrm{DMF}=0$ & 452 & $202(44.7)$ & 1 & 1 \\
\hline $\mathrm{DMF}>0$ & 299 & 157 (52.5) & $1.17(1.01-1.36)$ & $1.20(1.03-1.40)$ \\
\hline Self-rated oral health & 751 & 359 (47.8) & $p=0.03$ & $p=0.01$ \\
\hline Good-excellent & 373 & $193(51.7)$ & 1 & 1 \\
\hline Fair-poor & 378 & $166(43.9)$ & $0.84(0.73-0.98)$ & $0.82(0.71-0.96)$ \\
\hline
\end{tabular}

** Variables not fitted in the final multiple model after the adjustment. vice (private/public) and socioeconomic and psychosocial factors (Table 3). Most subjects had sought public service $(61.2 \%)$. The children who rated their oral health as "fair/poor," who were from a low-income household, and whose mothers did not complete primary education had been assisted by public service more often than their counterparts.

\section{Discussion}

In this study, we analyzed the complex association between the different determinants for dental visits by schoolchildren. In this study, $47.8 \%$ of the subjects had visited the dentist within the previous 6 months. This result is in accordance with a previous Brazilian study that documented a $46.8 \%$ prevalence of regular use of dental care service. ${ }^{6}$ Studies in other developing countries have reported a $27.7 \%$ prevalence among children in $\mathrm{Mexico}^{2}$ and a $1.7 \%$ prevalence in the suburban African schools. ${ }^{17}$
In Spain and the United States, both of which are developed countries, a $40 \%$ and more than $50 \%$ prevalence of regular use of dental service, respectively, was observed. ${ }^{10,18}$ In both developing and developed countries, a clear association between socioeconomic status and use of dental care system is demonstrated. ${ }^{1,2,10,11,18}$ However, few studies have investigated the relation between socioeconomic and psychosocial factors for dental healthcare utilization in a representative sample of Brazilian schoolchildren.

It was found that the use of dental service was strongly associated with socioeconomic, psychosocial and clinical factors. In general, children with lower socioeconomic status, dental caries and poor self-perception of oral health were less likely to have been to the dentist.

The underlying impact of socioeconomic conditions on different health outcomes is widely recog- 
Table 3 - Type of healthcare used (private/public) and associated factors (Prevalence ratio: $\mathrm{Cl}$ 95\%).

\begin{tabular}{|c|c|c|c|c|}
\hline \multirow{2}{*}{ Variables } & \multirow{2}{*}{$\mathrm{n}$} & \multicolumn{3}{|c|}{ Type of healthcare (PR for public) } \\
\hline & & n (\%) & $\mathrm{PR}(\mathrm{Cl} 95 \%)$ & $P R_{\text {adj }} \cdot(\mathrm{Cl} 95 \%)$ \\
\hline Sex & 745 & $456(61.2)$ & $p=0.10$ & $* *$ \\
\hline Boys & 328 & $190(57.9)$ & 1 & \\
\hline Girls & 417 & $266(63.8)$ & $1.10(0.97-1.23)$ & \\
\hline Skin colour & 738 & $452(61.2)$ & $p<0.01$ & $* *$ \\
\hline White & 577 & $336(58.2)$ & 1 & \\
\hline Non-white & 161 & $116(72.0)$ & $1.23(1.09-1.39)$ & \\
\hline Household income & 633 & $399(63.0)$ & $p<0.01$ & $p<0.01$ \\
\hline$\geq 2$ Brazilian minimum wages & 330 & $154(46.7)$ & 1 & 1 \\
\hline$<2$ Brazilian minimum wages & 303 & $245(80.9)$ & $1.73(1.52-1.96)$ & $1.51(1.33-1.72)$ \\
\hline Mother's education & 722 & $441(61.1)$ & $p<0.01$ & $p<0.01$ \\
\hline$\geq 8$ years & 317 & $137(43.2)$ & 1 & 1 \\
\hline$<8$ years & 415 & $304(75.1)$ & $1.73(1.51-1.99)$ & $1.50(1.30-1.72)$ \\
\hline Father's education & 699 & $420(60.1)$ & $p<0.01$ & $* *$ \\
\hline$\geq 8$ years & 263 & $115(43.7)$ & 1 & \\
\hline$<8$ years & 436 & $305(69.9)$ & $1.59(1.37-1.85)$ & \\
\hline Dental caries & 745 & $456(61.2)$ & $p=0.01$ & \\
\hline $\mathrm{DMF}=0$ & 450 & $259(57.6)$ & 1 & \\
\hline $\mathrm{DMF}>0$ & 295 & $197(66.8)$ & $1.16(1.03-1.29)$ & \\
\hline Self-rated oral-health & 745 & $456(61.2)$ & $p<0.01$ & $p<0.01$ \\
\hline Good-excellent & 371 & $206(55.5)$ & 1 & 1 \\
\hline Fair-poor & 374 & $250(66.8)$ & $1.20(1.07-1.35)$ & $1.16(1.04-1.30)$ \\
\hline
\end{tabular}

** Variables not fitted in the final multiple model after the adjustment.

nized. ${ }^{19-23}$ Socioeconomic inequalities could affect oral health, at both the individual and population levels, and by psychosocial or material deprivation causal pathways. ${ }^{19,24}$ In this study, increased socioeconomic disadvantage was related to decreased healthcare assistance. After the multiple regression analyses, it could be shown that children whose mothers have lower education level visited the dentist less frequently than their counterparts. This confirms previous reports regarding important determinants of children's dental visits, such as the caregiver's educational level. ${ }^{1,11,18}$ It has been shown that the level of education may reflect a range of non-economic conditions such as the accumulation of knowledge which can influence the adoption of healthy habits or improve social conditions. ${ }^{19}$ Results from previous studies demonstrated that the parents who have had no further education presented lower levels of dental knowledge and posi- tive dental attitudes. ${ }^{25}$ A general improved level of education may mean that parents are more able to access appropriate sources of information. ${ }^{26}$ These factors, which may be related to health behaviors, may help explain why educational level is associated with dental care utilization..$^{1,5,11}$ Nevertheless, inadequate resources, such as income or knowledge, limit people's choices and their potential to gain control over decision-making. The perception of being constrained in deprived social and material conditions is likely to evoke chronic levels of stress and further erode the sense of life satisfaction. A low sense of control may indirectly influence health through behavioral pathways such as adequate utilization of dental service. ${ }^{26}$

The prevalence of children who had visited the dentist within the previous 6 months was associated with the self-perception of oral health and oral health status. In general, children who rated their 
oral health as "good/excellent" and those with dental caries were more likely to have visited the dentist as compared to their counterparts. Studies aiming to associate dental care service utilization with selfrated oral health in schoolchildren are scarce. Results from a study on 14- and 15-year-old Brazilian adolescents failed to relate utilization of dental service with perception of oral health. ${ }^{13}$ Other studies showed that the perception of oral health is directly affected by socioeconomic factors. ${ }^{13,15}$ Socioeconomic inequalities may be associated with different health outcomes. These inequalities may affect the utilization of dental care service because of underlying influences of psychosocial, environmental, and material deprivations.

The distribution of utilization by the type of oral healthcare (public or private) varied across socioeconomic groups. Most subjects used the public service $(61.2 \%)$.

The results reveal a pro-poor use of public healthcare. Data from official Brazilian publications showed that only $24.6 \%$ of the population had private health insurance. ${ }^{27}$ Moreover, private dental service in Brazil is expensive, and in general, only part of the population can afford it. These findings

\section{References}

1. Noro LR, Roncalli AG, Mendes Junior FI, Lima KC. [Use of dental care by children and associated factors in Sobral, Ceara State, Brazil]. Cad Saude Publica. 2008 Jul;24(7):1509-16.

2. Medina-Solis CE, Maupome G, del Socorro HM, Perez-Nunez R, Avila-Burgos L, Lamadrid-Figueroa H. Dental health services utilization and associated factors in children 6 to 12 years old in a low-income country. J Public Health Dent. 2008 Winter;68(1):39-45.

3. Muirhead VE, Quinonez C, Figueiredo R, Locker D. Predictors of dental care utilization among working poor Canadians. Community Dent Oral Epidemiol. 2009 Jun;37(3):199-208.

4. Pizarro V, Ferrer M, Domingo-Salvany A, Benach J, Borrell C, Pont A, et al. The utilization of dental care services according to health insurance coverage in Catalonia (Spain). Community Dent Oral Epidemiol. 2009 Feb;37(1):78-84.

5. Medina-Solis CE, Maupome G, Avila-Burgos L, Hijar-Medina M, Segovia-Villanueva A, Perez-Nunez R. Factors influencing the use of dental health services by preschool children in Mexico. Pediatr Dent. 2006 May-Jun;28(3):285-92. are in agreement with a recent study that reported that the worse-off people are more likely to use subsidized public service, indicating that an investment in healthcare or the allocation of resources to city areas may facilitate access for disadvantaged groups. ${ }^{28}$

This study included a representative sample of 792 12-year-old children enrolled in city public schools. However, nearly $85 \%$ of the children in this age group are enrolled in public schools. Therefore, we carefully considered generalizations for all 12-year-old children living in the city. The use of asking people only a single question to rate their oral health might be a limitation. However, studies have shown that the single-item perceived oral health rating is related to other self-reported measures of oral health, such as multi-item indicators. ${ }^{29}$ Therefore, a single-item self-perceived oral health rating is particularly appropriate to obtain information from children and adolescents. ${ }^{15}$

\section{Conclusion}

This study showed that socioeconomic gradients and psychosocial factors are important predictors for the utilization of oral health care service.

6. Freddo SL, Aerts DR, Abegg C, Davoglio R, Vieira PC, Monteiro L. [Oral hygiene habits and use of dental services among teenage students in a city in southern Brazil]. Cad Saude Publica. 2008 Sep;24(9):1991-2000.

7. Kramer PF, Ardenghi TM, Ferreira S, Fischer L de A, Cardoso L, Feldens CA. [Use of dental services by preschool children in Canela, Rio Grande do Sul State, Brazil]. Cad Saude Publica. 2008 Jan;24(1):150-6.

8. Instituto Brasileiro de Geografia e Estatística. Pesquisa Nacional por Amostra de Domicílios: síntese de indicadores - 2003 [internet]. [cited 2010 jun 6]. Available from: http://www.ibge.gov. br/home/estatistica/populacao/trabalhoerendimento/pnad2003/ sintesepnad2003.pdf.

9. Jiang H, Petersen PE, Peng B, Tai B, Bian Z. Self-assessed dental health, oral health practices, and general health behaviors in Chinese urban adolescents. Acta Odontol Scand. 2005 Nov;63(6):343-52.

10. Jimenez R, Tapias-Ledesma MA, Gallardo-Pino C, Carrasco $\mathrm{P}$, de Miguel AG. Influence of sociodemographic variables on use of dental services, oral health and oral hygiene among Spanish children. Int Dent J. 2004 Aug;54(4):187-92. 
11. Sohn W, Ismail A, Amaya A, Lepkowski J. Determinants of dental care visits among low-income African-American children. J Am Dent Assoc. 2007 Mar;138(3):309-18.

12. Araujo CS, Lima C, Peres MA, Barros AJ. [Use of dental services and associated factors: a population-based study in southern Brazil]. Cad Saude Publica. 2009 May;25(5):106372.

13. Pattussi MP, Olinto MT, Hardy R, Sheiham A. Clinical, social and psychosocial factors associated with self-rated oral health in Brazilian adolescents. Community Dent Oral Epidemiol. 2007 Oct;35(5):377-86.

14. Sanders AE, Slade GD. Deficits in perceptions of oral health relative to general health in populations. J Public Health Dent. 2006 Fall;66(4):255-62.

15. Perera I, Ekanayake L. Factors influencing perception of oral health among adolescents in Sri Lanka. Int Dent J. 2008 Dec;58(6):349-55.

16. World Health Organization. Oral health surveys: basic methods, $4^{\text {th }}$ ed. Geneva: WHO; 1997.

17. Adekoya-Sofowora CA, Nasir WO, Oginni AO, Taiwo M. Dental caries in 12-year-old suburban Nigerian school children. Afr Health Sci. 2006 Sep;6(3):145-50.

18. Vargas CM, Ronzio CR. Relationship between children's dental needs and dental care utilization: United States, 1988-1994. Am J Public Health. 2002 Nov;92(11):1816-21.

19. Braveman PA, Cubbin C, Egerter S, Chideya S, Marchi KS, Metzler M, et al. Socioeconomic status in health research: one size does not fit all. JAMA. 2005 Dec;294(22):2879-88.

20. Piovesan C, Mendes FM, Ferreira FV, Guedes RS, Ardenghi TM. Socioeconomic inequalities in the distribution of dental caries in Brazilian preschool children. J Public Health Dent. 2010 Aug 23; [Epub ahead of print]. DOI: 10.1111/j.17527325.2010.00191.x.

21. Amaral MA, Nakama L, Conrado CA, Matsuo T. Dental caries in young male adults: prevalence, severity and associated factors. Braz Oral Res. 2005 Oct-Dec;19(4):249-55.

22. Bonanato K, Pordeus IA, Moura-Leite FR, Ramos-Jorge ML, Vale MP, Paiva SM. Oral disease and social class in a random sample of five-year-old preschool children in a Brazilian city. Oral Health Prev Dent. 2010;8(2):125-132.

23. Watt RG. Emerging theories into the social determinants of health: implications for oral health promotion. Community Dent Oral Epidemiol. 2002 Aug;30(4):241-7.

24. Locker D. Deprivation and oral health: a review. Community Dent Oral Epidemiol 2000 Jun;28(3):161-9.

25. Williams NJ, Whittle JG, Gatrell AC. The relationship between socio-demographic characteristics and dental health knowledge and attitudes of parents with young children. $\mathrm{Br}$ Dent J. 2002 Dec;193(11):651-4.

26. Sanders AE, Spencer AJ. Why do poor adults rate their oral health poorly? Aust Dent J. 2005 Sep;50(3):161-7.

27. Pinheiro R, Torres T. [Access to oral health services between Brazilian States]. Cien Saude Colet. 2006 OctDec;11(4)999-1010.

28. Somkotra T, Detsomboonrat P. Is there equity in oral healthcare utilization: experience after achieving Universal Coverage. Community Dent Oral Epidemiol. 2009 Feb;37(1):85-96.

29. Atchison KA, Dolan TA. Development of the Geriatric Oral Health Assessment Index. J Dent Educ. 1990 Nov;54(11):6807. 